\title{
Gentian extract induces caspase-independent and mitochondria-modulated cell death
}

\author{
Mika Ogata $^{1}$, Kazushige Matsukawa ${ }^{2}$, Kiyomi Kogusuri ${ }^{1}$, Tetsuro Yamashita ${ }^{2}$, Takashi Hikage ${ }^{2,3}$, \\ Kikukatsu Ito ${ }^{1,2}$, Yasushi Saitoh ${ }^{1,2}$, Ken-ichi Tsutsumi ${ }^{1,2^{*}}$
}

${ }^{1}$ Cryobiofrontier Research Center, Iwate University, Morioka, Japan;

${ }^{2}$ United Graduate School of Agricultural Sciences, Iwate University, Morioka, Japan;

${ }^{3}$ Hachimantai City Floricultural Research and Development Center, Hachimantai, Japan.

Email: "kentsu@iwate-u.ac.jp

Received 23 September 2011; revised 25 October 2011; accepted 3 November 2011.

\begin{abstract}
Extracts from the dried roots of gentian plant, Gentiana triflora, exhibit an antiproliferative activity against cultured and implanted tumor cells. However, the underlying mechanism has been unclear. In the present study, we show that the cell death induced by the extract occurs caspase-independently and depends on metabolic status of mitochondrial respiration. We observed that sensitivity to the extract was considerably lower in HeLa cells, which have a low rate of mitochondrial respiration, in comparison to Y3-Ag1.2.3 cells, which have a higher rate of respiration. Furthermore, sensitivity of HeLa cells to the extract increased significantly when they were forced to switch their energy dependency from glycolysis to mitochondrial respiration. These results indicate that the gentian extract targets on mitochondrial respiration. Consequently, different respiratory activities in mitochondria confer cells to have different susceptibilities to the extract-induced cell death.
\end{abstract}

Keywords: Antiproliferative Activity; Cell Death; Mitochondria; Respiration; Gentiana triflora

\section{INTRODUCTION}

As a typical form of cell death, apoptosis has been extensively characterized. However, reports concerning to additional types of cell death are accumulating, and the pathways for cell death are now thought to be far more diverse than predicted [1-3]. Despite such diverse pathways, the mitochondria act in many cases as a relay point that transmits different signaling for cell death, with the final outcome of the mitochondria depending on the cell types. Accordingly, the metabolic condition of the mitochondria modulates both apoptotic [4-7] and non-apoptotic cell death [8-12]. Highly proliferative can- cer cells derive most their energy from glycolysis rather than from mitochondrial respiration [13-19]. Those cancer cells are adapted for survival by using various pathways to avoid cell death $[20,21]$. Upregulated glycolysis, for example, activates the serine/threonine kinase Akt, conferring resistance to antiproliferative drugs $[6,22]$. Susceptibility of cells to antiproliferative drugs is also modulated by mitochondrial respiration. A high concentration of glucose in culture strongly inhibits mitochondrial respiration in most cancer cells, a phenomenon called the Crabtree effect [23]. Those cells exhibit resistance to mitochondrial toxicants such as antimycin and oligomycin. Circumventing the Crabtree effect by growing in glucose-deprivated galactose media $[24,25]$, cells become susceptible to the toxicants [26]. Collectively, glycolysis and mitochondrial respiration are directly or indirectly involved in cell death and survival signaling.

Previously, we reported that extracts from dried roots of Gentiana triflora, an ingredient in Chinese herbal medicine [27], exhibit cell death-inducing activity against cultured tumor cells and antiproliferative activity against implanted tumor cells [28]. The underlining mechanism, however, has been unknown. Here, we show that the extract-induced cell death occurs caspase-independently and depends on mitochondrial state of energy metabolism.

\section{MATERIALS AND METHODS}

\subsection{Plant Materials and Extract Preparation}

The gentian plant used in this study was Gentiana triflora var. japonica, which was provided by the Hachimantai City Floricultural Research and Development Center, Hachimantai, Iwate 028-7592, Japan. Preparation of gentian root extract and its cell antiproliferative activity has been described previously [28]. Dried roots were powdered and extracted sequentially with 10 times volume $(\mathrm{w} / \mathrm{v})$ of chloroform at $50^{\circ} \mathrm{C}$, methanol at $50^{\circ} \mathrm{C}$, 
and boiling water for $30 \mathrm{~min}$. Each extraction was repeated twice. After cooling, the extract was vacuumdried, dissolved in methanol or water (for boiling-water extract) at a concentration of $20 \mathrm{mg} / \mathrm{ml}$, and centrifuged at $14.000 \times \mathrm{g}$ for $30 \mathrm{~min}$ to discard insoluble fibrous materials. The boiling-water extract was autoclaved for 20 min at $121^{\circ} \mathrm{C}$, and passed through a $0.22 \mathrm{~mm}$ filter. The extracts were stored at $4^{\circ} \mathrm{C}$ in the dark.

\subsection{Cells and Culture Conditions}

Y3-Ag1.2.3 cells derived from rat myeloma were purchased from Health Science Research Resources Bank (JCRB9091, Osaka, Japan) and were cultured in Dulbecco's modified Eagle's medium (DMEM) containing $25 \mathrm{mM}$ glucose and supplemented with 5\% fetal bovine serum (FBS). Human HeLa and rat dRLh84 cells were cultured in DMEM supplemented with 10\% FBS and newborn bovine serum (NBS), respectively. Daudi and 3Y1-B1-6 cells were cultured in DMEM supplemented with 5\% FBS. For culturing HeLa and Y3-Ag1.2.3 cells in galactose, the glucose in each medium was replaced by $10 \mathrm{mM}$ galactose and supplemented with $1 \mathrm{mM}$ sodium pyruvate [18]. Cells were maintained in the galactose medium for more than 10 passages prior to the experiments.

\subsection{Cell Proliferation Assay}

Cell proliferation was measured either by counting viable cells with a trypan blue exclusion assay, or by a WST-1 (4-[3-(4-iodophenyl)-2-(4-nitrophenyl)-2H-5-tetrazolio]-1, 3-benzene disulfonate) assay according to the supplier's protocol (Cell Counting Kit, DOJINDO, Japan). Briefly, cells ( 1 to $2 \times 10^{4}$ ) were seeded in $100 \mathrm{ml}$ of medium in a 96-well plate in the presence or absence of gentian root extracts. After culturing for 24 to $48 \mathrm{hr}$ at $37^{\circ} \mathrm{C}$ in a $\mathrm{CO}_{2}$ incubator, $10 \mathrm{ml}$ of WST-1 reagent was added, followed by additional 2 to $4 \mathrm{hr}$ of incubation at $37^{\circ} \mathrm{C}$. After that, colorimetric measurements were performed at $450 \mathrm{~nm}$ and $650 \mathrm{~nm}$ (for reference) using a plate reader apparatus (Multiscan JX, Thermobio Analysis Co., Tokyo). The relative number of viable cells was expressed as a percentage of the control, based on the absorbance at $450 \mathrm{~nm}$.

\subsection{Inhibition of Caspase Activity and Detection of Cytochrome C}

The pan-caspase inhibitor Z-VAD-fmk [benzyloxycarbonylvalyl-alanyl-aspartic acid (O-methyl)-fluoro-methylketone, Peptide Institute Inc., Osaka, Japan] was used to determine the caspase dependency of cell death. Cells were plated at a density of 1 to $2 \times 10^{4}$ per $100 \mathrm{ml}$ in a 96-well plate and cultured in the presence of gentian extract and 0 to $50 \mathrm{mM} \mathrm{Z-VAD-fmk}$ for the indicated times in a $\mathrm{CO}_{2}$ incubator. The number of viable cells was measured with either the WST-1 assay or trypan blue exclusion, as described above. Cytoplasmic and mitochondrial cytochrome c were detected by a Cytochrome C Release Apoptosis Assay Kit (Oncogene, San Diego, USA), according to the manufacturer's protocol. Equal amounts (10 mg) of cytoplasmic and mitochondrial proteins were subjected to SDS-polyacrylamide gel electrophoresis, followed by Western blotting using an anti-cytochrome c antibody, and the ECL Western Blotting Analysis System (Amersham Pharmacia Biotech).

\subsection{Flow Cytometric Analysis of Mitochondrial Transmembrane Potential $(\Delta \psi \mathrm{m})$ and Mitochondrial Mass}

Mitochondrial transmembrane potential ( $\Delta \psi \mathrm{m})$ and mitochondrial mass were analyzed by staining cells with 200 nM MitoTracker Red CMXRos [Molecular Probes Inc. (Invitrogen)] and 200 nM MitoTracker Green FM (Molecular Probes Inc.), respectively, according to the manufacturer's protocols. MitoTracker Red accumulates in the mitochondrial matrix under the influence of the changes in mitochondrial membrane potential. MitoTracker Green selectively accumulates in the mitochondrial matrix where it binds covalently to mitochondrial proteins. Mitochondrial $\Delta \psi \mathrm{m}$ and mass-related fluorescence was measured using an FL1 photomultiplier and a FACS Calibur flow cytometer. The measurements were performed at least in triplicate for each dye, and the values were expressed as arbitrary scanning units of fluorescence at the peak of cell populations.

\subsection{Measurements of Oxygen Consumption}

Oxygen consumption in intact cells was measured as an activity of mitochondrial respiration as previously described [29]. After the growth under different culture conditions, 1 to $5 \times 10^{6}$ cells were resuspended in $1 \mathrm{ml}$ of fresh culture medium and placed in the sealed respiration chamber equipped with a thermostat and microstirrer. Oxygen consumption was measured polarographically at $37^{\circ} \mathrm{C}$ using the Clark-type oxygen electrode disk, according to the procedures recommended by the manufacturer (Oxy1, Hansatech Instrument Inc., UK). The respiration rate was expressed as nmoles of $\mathrm{O}_{2}$ consumed per $10^{6}$ cells as a function of time (min).

\subsection{Statistical Analysis}

In most cases, data are expressed as mean \pm S.D. from at least three independent experiments. Statistical comparisons were performed by one-way ANOVA. The results were considered significant at a value of $\mathrm{p}<0.05$. 


\section{RESULTS AND DISCUSSION}

\subsection{Antiproliferative Activity of Gentian Extract Differs among Tumor Cell Types}

Gentian extracts were prepared by sequential extraction with chloroform, methanol, and boiling-water. The antiproliferative activity was found in boiling-water extract and, to a lesser extent, methanol extract. In the following, all experiments were carried out using the boiling-water extract.

The antiproliferative activity of the boiling-water extract from gentian roots was assayed for different cell types. As shown in Figure 1, the activity differed among target cell types. For example, Y3-Ag1.2.3 (rat myeloma) and Daudi cells (human Burkitt's lymphoma) exhibited high sensitivities to the extract, while HeLa (human cervical cancer), dRLh84 (rat hepatoma), and 3Y1B1-6 (rat embryonic fibroblast) cells showed considerably lower sensitivities by comparison to Y3-Ag1.2.3 cells. Such a cell type-dependent susceptibly to antiproliferation has not been observed so far for gentian extract. Why the activity is distinctive for different cell types is unknown at present. One possibility may arise that metabolic status of the cells correlates with their sensitivities to antiproliferative or death-inducing compound(s), similar

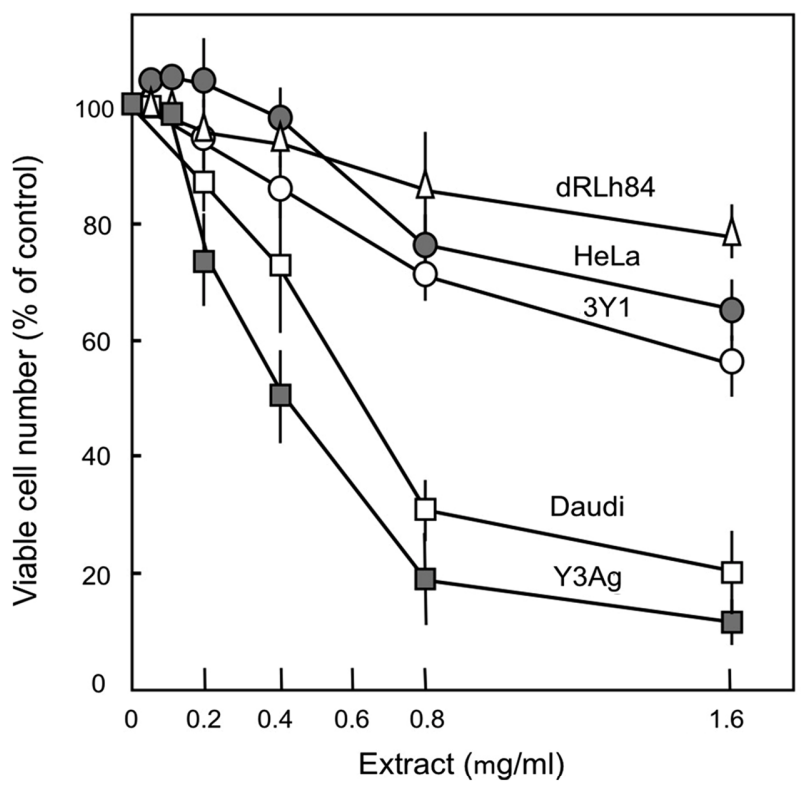

Figure 1. Antiproliferative activity of gentian extract against different cancer cell lines. HeLa (human), 3Y1B1-6 (rat, show$\mathrm{n}$ as 3Y1), dRLh84 (rat), Daudi (human) and Y3-Ag1.2.3 (rat, shown as Y3Ag) cells were plated at a density of $1 \times 10^{4}$ cells per $100 \mathrm{l}$ medium and cultured for $48 \mathrm{hr}$ in the presence of increasing concentrations of the gentian extract. The relative number of viable cells was determined by staining with trypan blue, and expressed as a percentage of the control (without extract). Data are averages of three independent experiments. Error bars represent value ranges. to different activities of mitochondrial toxicants against HepG2 cell with different energy metabolism [26].

In the following experiments, Y3-Ag1.2.3 and HeLa cells were used as typical cancer cell lines exhibiting high and low sensitivity against the extract, respectively.

\subsection{Cell Death Induced by Gentian Extract is Caspase-Independent}

To elucidate the mechanism of the antiproliferative action of the extract, characteristic features of apoptosis were examined using Y3-Ag1.2.3 cells. Firstly, to see whether the activity depends on caspase or not, the effect of a pan-caspase inhibitor, Z-VAD-fmk, on extract- induced cell death was examined (Figure 2(a)). As a control experiment, rescue of apoptosis by the inhibitor was monitored in parallel, using the cells treated with a known apoptosis inducer, campthotecin (CPT) [30]. The results showed that, while $50 \mathrm{mM} \mathrm{Z-VAD-fmk} \mathrm{almost}$ completely inhibited CPT-induced apoptosis, it did not affect the extract-induced cell death. Thus, the extractinduced cell death could be caspase-independent. Change in the cellular localization of cytochrome c was also examined (Figure 2(b)). Equal amounts of proteins from mitochondrial and cytoplasmic fractions of the extractor CPT-treated cells were subjected to Western blotting using anti-cytochrome c antibodies. Cytoplasmic cytochrome c increased after the cells were treated with 10 $\mathrm{mM}$ CPT for 3 to $7 \mathrm{hr}$. In contrast, even at higher concentrations $(5 \mathrm{mg} / \mathrm{ml})$, the gentian extract did not induce the release of cytochrome $\mathrm{c}$ from mitochondria within the time examined. It is not clear at present whether the extract contains a factor(s) that inhibits release of cytochrome c from mitochondria, similar to that reported for aqueous extract of the Chinese medicine, Danggui-Shaoyao-San [31].

We next examined the change in mitochondrial transmembrane potential ( $\Delta \psi \mathrm{m})$ during the process of the extract-induced cell death. Cells treated with CPT or oligomycin were also examined. Oligomycin is an inhibitor of the $\mathrm{F}_{1} \mathrm{~F}_{\mathrm{o}}$-ATPase, which is integrated in the inner mitochondrial membrane; it inhibits proton transport from intermembrane space into matrix and ATP synthesis, resulting in increased $\Delta \psi \mathrm{m}$ (Figure 2(c), right). As shown in Figure 2(c) (left), $\Delta \psi \mathrm{m}$ increased in Y3-Ag1.2.3 cells after treatment with the extract, while that of cells treated with the apoptosis-inducer CPT significantly decreased (Figure 2(c), right). These results implied that gentian extract acts on mitochondrial energy production in a manner similar to oligomycin. Oligomycin has been known to induce caspase-independent cell death via mitochondria-emanating effectors and $\mathrm{Bax} \mathrm{BH}$ domain [32], as well as to inhibit $\mathrm{F}_{1} \mathrm{~F}_{\mathrm{o}}$-ATPase. However, such an oligomycin-like activity has not, to to our knowl 

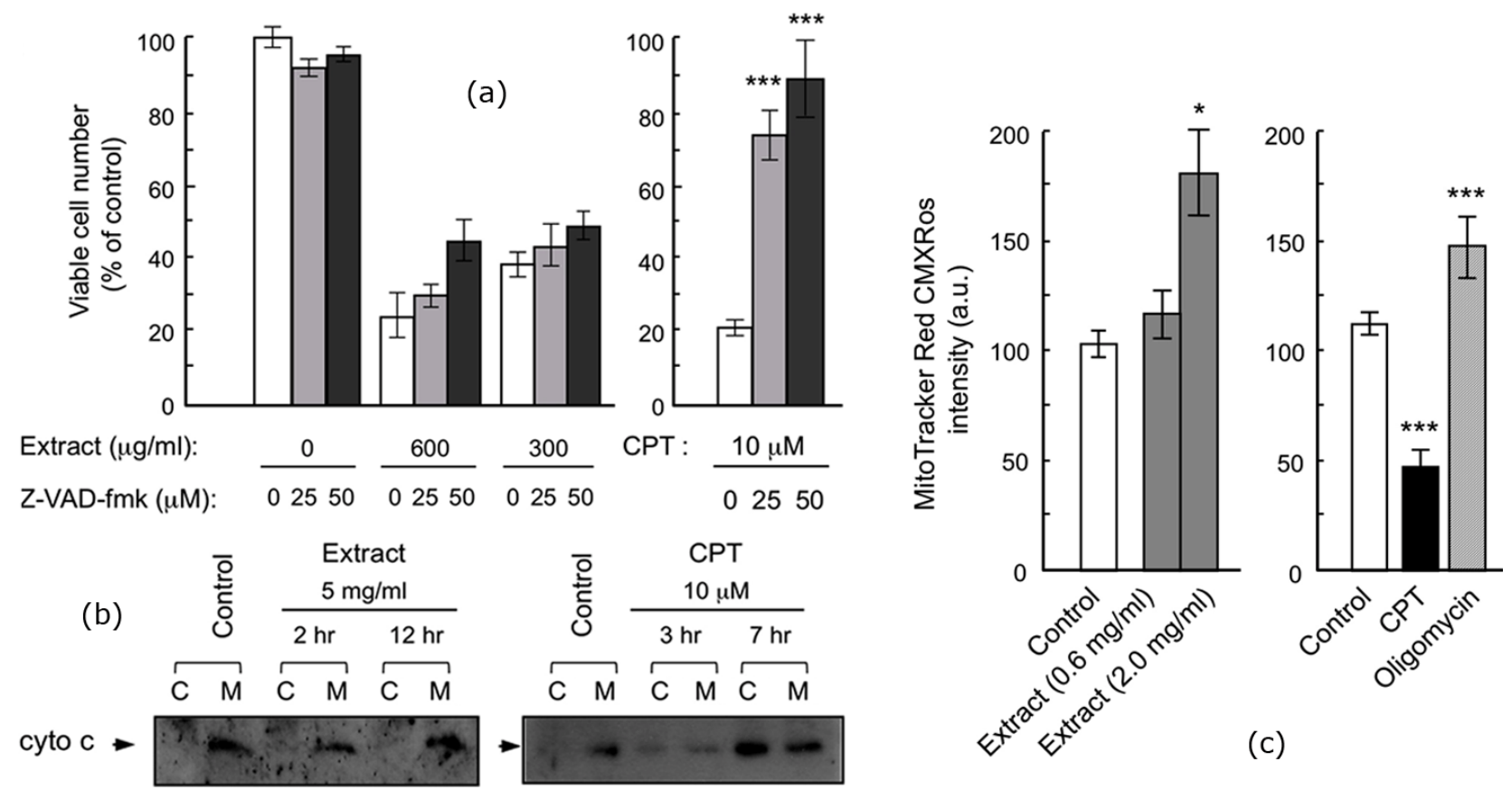

Figure 2. Cell death induced by gentian extract does not proceed via typical apoptotic pathways. (a) Effect of a pan-caspase inhibitor, Z-VAD-fmk, on the extract-induced cell death. Y3-Ag1.2.3 cells (Y3Ag) were cultured for $48 \mathrm{hr}$ in the presence of gentian extract (extract) and Z-VAD-fmk at the concentrations indicated. As a control experiment, Y3-Ag1.2.3 cells were treated with a known apoptosis inducer, campthotecin (CPT), at $10 \mathrm{M}$ for $24 \mathrm{hr}$ in the presence or absence of Z-VAD-fmk. The relative number of viable cells was determined by a WST-1 assay and expressed as a percentage of the control. (b) Release of cytochrome c from mitochondria after incubation with gentian extract (left) or CPT (right). Y3-Ag1.2.3 cells were cultured in the presence or absence of gentian extract or CPT for the indicated times. Equal amounts (10 g) of proteins from mitochondrial (M) and cytoplasmic (c) fractions (see Materials and methods) were subjected to Western blotting with an anti-cytochrome c antibody. (c) Changes in mitochondrial transmembrane potential ( $\Delta \psi \mathrm{m}$ ) in Y3-Ag1.2.3 cells after growth in the presence of gentian extract, camptothecin (CPT) and oligomycin. Cells were cultured in the presence of $0.6 \mathrm{mg} / \mathrm{ml}$ and $2 \mathrm{mg} / \mathrm{ml}$ gentian extract for $21 \mathrm{hr}, 10 \mathrm{M} \mathrm{CPT}$ for $7 \mathrm{hr}$, and $25 \mathrm{M}$ oligomycin for $3 \mathrm{hr}$. m was measured using MitoTracker Red CMXRos as described in Materials and methods. Data are averages of four to six independent experiments, and are expressed as mean \pm S.D. *Statistically significant, $\mathrm{P}<0.05$, $* * * \mathrm{P}<0.001 .50$.

edge, been reported for extracts/compounds from plants. The results obtained from the HeLa cells were consistent with a previous report [25]. We examined whether mitochondrial energy metabolism, such as oxidative phosphorylation, affects the antiproliferative activity of the extract.

\subsection{Activation of Mitochondrial Respiration After Adaptation to Grow in Galactose Medium}

Cancer cells are generally characterized by a high glycolytic activity and a low oxidative phosphorylation (respiration) in mitochondria [13,14,24]. From the results described above, we hypothesized that low levels of mitochondrial energy metabolism affect the susceptibility of cells to extract-induced death. To test this, the sensitivities of the cells to the extract were examined after mitochondrial respiratory activity was forced to increase by culture conditions. This experiment was conducted based on the observations that the lowered activity of mitochondrial respiration in cancer cells can be reactivated by growth in a medium in which glucose is replaced by galactose $[25,26]$.
To confirm that growth in galactose medium alters mitochondrial functions in HeLa and Y3-Ag1.2.3, the cells grown in galactose were assayed for their growth rates, oxygen consumption, mitochondrial mass and transmembrane potential $(\Delta \psi \mathrm{m})$. As shown in Figure 3, HeLa cells showed different growth rates when cultured in glucose and galactose media (about 2.6-fold prolonged doubling time in galactose). However, Y3-Ag1.2.3 cells exhibited a similar doubling time in glucose and galactose during the exponentially growing phase.

The rate of oxygen consumption differed between HeLa and Y3-Ag1.2.3 cells grown in standard glucose medium (Figure 4(a)). Y3-Ag1.2.3 cells exhibited a higher rate of oxygen consumption than HeLa cells by about 1.7-fold. When grown in glucose-deprivated galactose medium, oxygen consumption rate increased by about 2.1- and 1.3-fold in HeLa and Y3-Ag1.2.3 cells, respectively. Galactose-grown HeLa cells reached to a similar range in the oxygen consumption rate to that of glucose-grown Y3-Ag1.2.3 cells. Thus, the cells grown in galactose medium enhanced their aerobic metabolism in 

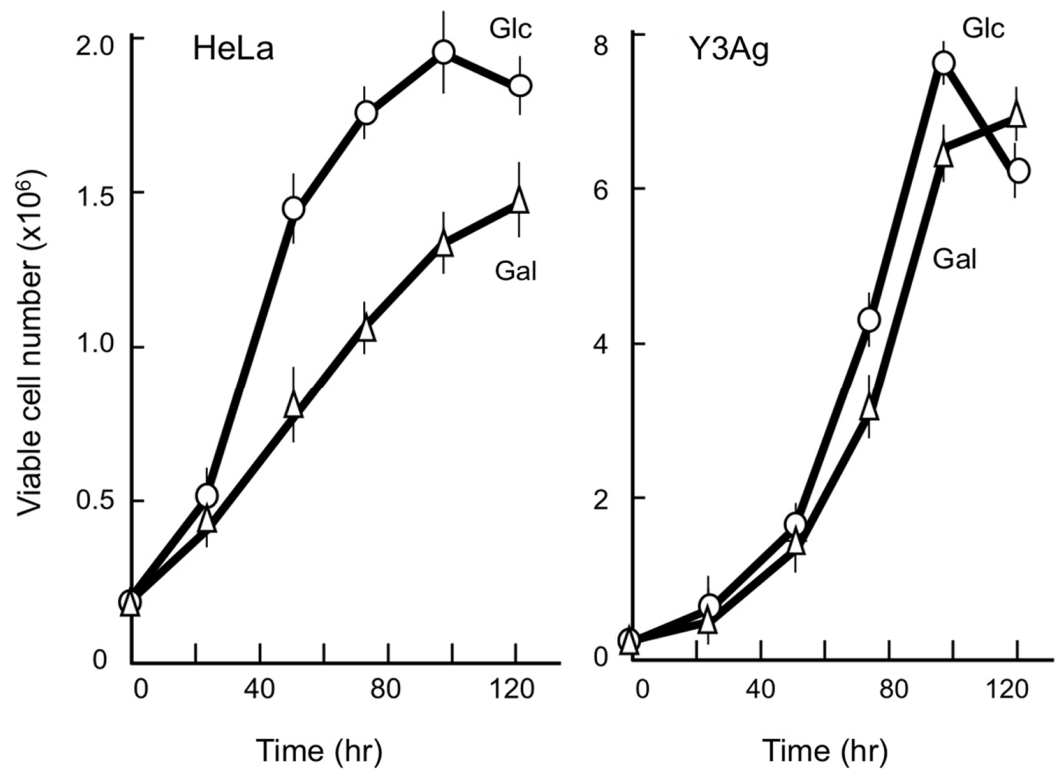

Figure 3. Proliferation of cells in different sugar media. HeLa (left) and Y3-Ag1.2.3 cells (right) were grown in DMEM containing glucose (Glc, circle) or galactose (Gal, triangle). Glucose concentrations in media for HeLa and Y3-Ag1.2.3 cells were $5.5 \mathrm{mM}$ and $25 \mathrm{mM}$, respectively. Galactose concentration was $10 \mathrm{mM}$ for both cell lines. The number of viable cells was counted by trypan blue staining, and the presented values are the averages of three independent experiments. Error bars denote value ranges.

(a) $\mathrm{O}_{2}$ consumption

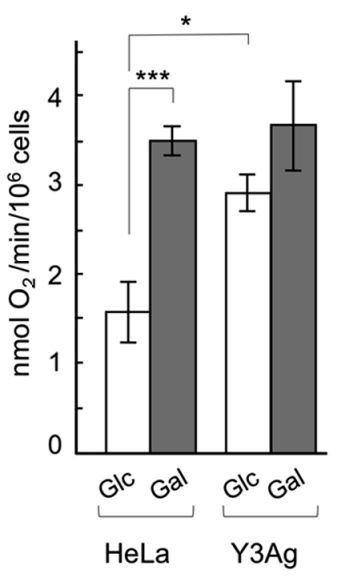

(b) $\Delta \Psi \mathrm{m}$

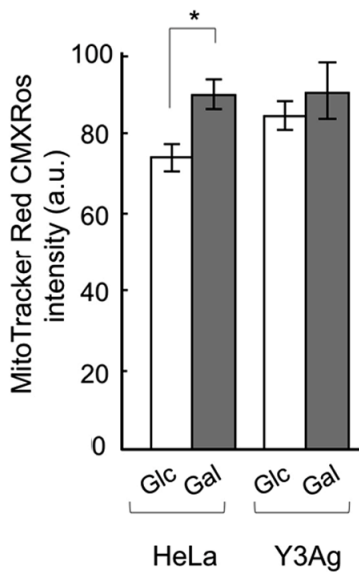

(c) Mass

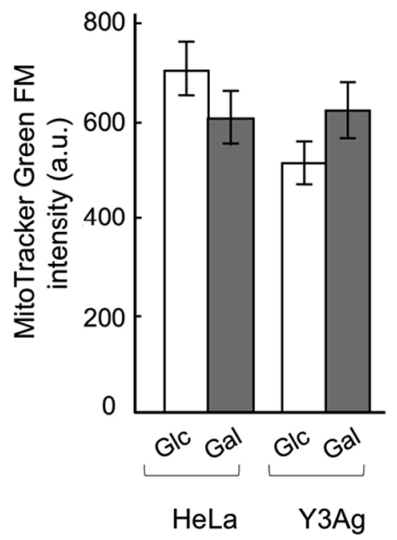

Figure 4. Mitochondrial activities of HeLa and Y3-Ag1.2.3 cells grown in glucose (Glc) or galactose media (Gal). Concentrations of glucose and galactose were as described in the legend to Figure 3. Oxygen consumption (a), mitochondrial transmembrane potential ( $\Delta \psi \mathrm{m}, \mathrm{b})$, and mitochondrial mass (c) were measured as described in Materials and Methods. Mitochondrial $\Delta \psi \mathrm{m}$ and mass-related fluorescences were measured by FCM using an FL1 photomultiplier. Presented values were the averages of three to six independent experiments, and are expressed as mean \pm S.D. *Statistically significant, $\mathrm{P}<0.05$, *** $\mathrm{P}<0.001$.

mitochondria. The results obtained from the HeLa cells were consistent with a previous report [25].

$\Delta \psi \mathrm{m}$ in galactose-grown HeLa cells increased slightly, while Y3-Ag1.2.3 cells showed no significant chan- ge, as compared to their glucose-grown counterparts (Figure 4(b)). Cells grown in glucose and galactose had no statistically significant difference in their mitochondrial masses (Figure 4(c)). 


\subsection{Cells with Increased Respiration Rates Become More Sensitive to Gentian Extract}

To determine whether an increased rate of mitochondrial respiration affects the susceptibility of the cells to extract-induced death, HeLa and Y3-Ag1.2.3 cells were cultured in glucose and in galactose media in the presence or absence of the extract. As shown in Figure 5 (left), HeLa cells cultured in galactose medium exhibited a significantly higher susceptibility to extract-induced cell death, as compared with those cultured in glucose. The $50 \%$ effective concentration $\left(\mathrm{EC}_{50}\right)$ of the extract for HeLa cells in glucose media was calculated to be approximately $2.0 \mathrm{mg} / \mathrm{ml}$. This value was significantly reduced $(0.6 \mathrm{mg} / \mathrm{ml}-0.7 \mathrm{mg} / \mathrm{ml})$ after the cells were adapted to grow in galactose. Based on the $\mathrm{EC}_{50}$ values, the sensitivity of HeLa cells to the extract-triggered death in galactose medium had increased nearly 3-fold higher than that in glucose medium. The increased sensitivity of HeLa cells is due to altered energy metabolism in galactose medium, since the extract by itself did not affect oxygen consumption in galactose medium (data not shown). Proliferation of Y3-Ag1.2.3 cells was also inhibited more when the cells were grown in galactose medium. However, this increased sensitivity was seen only at higher concentrations of the extract, and the levels of increase were not as high as that of HeLa cells (Figure 5, right).
The results presented here indicated that the gentian extract does neither induce release of cytochrome c from the mitochondria, decrease in mitochondrial transmembrane potential, nor activation of caspases. Previous data showed that the extract triggers large-scale chromosomal fragmentation but not oligonucleosomal DNA fragmentation (DNA ladder) [28]. These observations do not entirely exclude a possibility that the extract induces cell death via apoptosis, since several caspase-independent apoptotic pathways have also been known [33,34]. However, increase in $\Delta \psi \mathrm{m}$ (Figure 2(c)) implies the extract-induced cell death to be other than apoptosis, because, apoptotic pathway involves dissipation (not increase) of $\Delta \psi \mathrm{m}$, which means mitochondrial transmembrane permeabilization, i.e., one of the biochemical aspects of distinct modalities of apoptosis [35].

Using HeLa and Y3-Ag1.2.3 cells as the representative cell lines with low and high sensitivity to the extract, respectively, correlation of the antiproliferative activity of the extract to the metabolic circumstances in the mitochondria was examined. The sensitivity of HeLa cells was approximately 5-fold lower than Y3-Ag1.2.3 cells. However, HeLa cells become more sensitive after adaptation for growth in galactose medium, a condition under which mitochondrial respiration (oxidative phosphorylation) increased by about two-fold. Thus, the resistance of HeLa cells to the extract seems to correlate with low levels of oxidative phosphorylation. The extract most

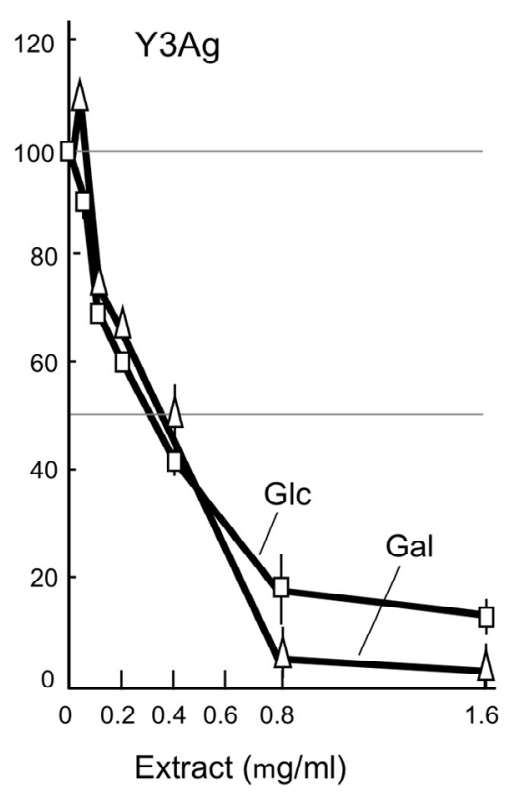

Figure 5. Effect of gentian extract on the growth of cells cultured in different sugar media. HeLa (left) or Y3-Ag1.2.3 cells (right) were grown in glucose or galactose media for $48 \mathrm{hr}$ in the presence of increasing concentrations of the extract. The relative number of viable cells was counted by trypan blue exclusion. Values were the averages of three to four independent experiments, and were expressed as a percentage of the control. Error bars represent value ranges. 
likely abrogated a step(s) in the mitochondrial energy metabolism, and the extract-induced cell death proceeded via increased $\Delta \psi \mathrm{m}$ in a way similar to the action of oligomycin [36]. Therefore, the extract did not efficiently act on cells with low levels of oxidative phosphorylation.

In contrast, the cell death-inducing effects of the extract on Y3-Ag1.2.3 cells increased only slightly after the cells were adapted for growth in galactose medium. The following explanation may be plausible for this. As described earlier, oxygen consumption in Y3-Ag1.2.3 cells is considerably higher than in HeLa cells in standard growth conditions (glucose medium), and the increase of that in galactose medium is less significant as compared to that in HeLa cells. In addition, the rate of oxygen consumption in Y3-Ag1.2.3 cells in glucose is in a similar range to that in HeLa cells in galactose medium. Thus, Y3-Ag1.2.3 cells per se appear to have an innate physiological state in mitochondrial energy metabolism, which is responsible for a nearly maximal level of susceptibility to the gentian extract, hence the limited increase in susceptibility to death in galactose medium.

Critical roles for the mitochondrial respiratory chain in cell death have been demonstrated by several groups. A recent report showed that defects in the ability to carry out oxidative phosphorylation render HepG2 cells become more resistant to mitochondrial toxicants such as rotenone, antimycin and oligomycin [26]. In cell death triggered by ER stress and DNA damage, oxidative phosphorylation is required for the activation of Bax and Bak, which are essential for alteration of mitochondrial membrane permeability [37]. Consequently, cancer cells with very low levels of oxidative phosphorylation are unable to activate Bax and Bak, and thus, are able to evade cell death signals. Kwong et al. [7] also reported that cells lacking respiratory chain were protected against both mitochondrial- and ER stress-induced apoptosis. The action of the gentian extract on HeLa and Y3-Ag1.2.3 cells does not contradict the observations described above.

The responsive gentian compound is yet to be identified, although it has small molecular mass and is water-soluble. Gentian plants contain several characteristic small compounds, including gentiopicrosides, gentisic acid, oligosaccharides (gentianose and gentiobiose), and glucosides. Those are known for various activities such as inhibitor of aldose reductase, inhibitor of platelet activating factor (PAF), and scavenger of free radicals [27]. However, cell death-inducing or antiproliferative activity has not been reported for those compounds. Chromatographic behavior and mass spectroscopic analysis suggested that the cell death-inducing compound relates to gentiopicroside or its derivatives. However, commercially available gentiopicroside did not show such an activity. Structure of the responsive compound(s) remains to be elucidated in the future.

\section{CONCLUSIONS}

The gentian extract-induced cell death occurs in a caspase-independent pathway and in a manner depending on energy metabolism, i.e., cells with low rate of mitochondrial respiration had lower susceptibility to the extract-induced cell death as compared to those with higher level of mitochondrial respiration. This was confirmed by the fact that sensitivity to the extract increased significantly when cells were forced to switch their energy dependency from glycolysis to mitochondrial respiration. Thus, the extract targets on mitochondrial respiration, so that different mitochondrial activities confer cells to have different susceptibilities to the extract-induced cell death.

\section{ACKNOWLEDGEMENTS}

We thank the Hachimantai City Floricultural Research and Development Center for providing gentian plants and dried roots. We also thank Dr. R. Tsutsumi at Iwate Medical University School of Medicine for her help and discussion.

\section{REFERENCES}

[1] Kumar, A. and Rothman, J.H. (2007) Cell death: Hook, line and linker. Current Biology, 17, R286-R289. doi:10.1016/j.cub.2007.02.032

[2] Yuan, J. and Kroemer, G. (2010) Alternative cell death mechanisms in development and beyond. Genes \& Development, 24, 2592-2602. doi:10.1101/gad.1984410

[3] Orrenius, S., Nicotera, P. and Zhivotovsky, B. (2011) Cell death mechanisms and their implications in toxicology. Toxicological Sciences, 119, 3-9. doi:10.1093/toxsci/kfq268

[4] Pelicano, H. Feng, L., Zhou, Y., Carew, J.S., Hileman, E. O., Plunkett, W., Keating, M. J. and Huang, P. (2003) Inhibition of mitochondrial respiration: A novel strategy to enhance drug-induced apoptosis in human leukemia cells by a reactive oxygen species-mediated mechanism. Journal of Biological Chemistry, 278, 37832-37839. doi:10.1074/jbc.M301546200

[5] Gatenby, R.A. and Gillies, R.J. (2004) Why do cancers have high aerobic glycolysis? Nature Review of Cancer, 4, 891-899. doi:10.1038/nrc1478

[6] Pelicano, H., Xu, R.H., Du, M., Feng, L., Sasaki, R., Carew, J.S., Hu, Y., Ramdas, L., Hu, L., Keating, M.J., Zhang, W., Plunkett, W. and Huang, P. (2006) Mitochondrial respiration defects in cancer cells cause activation of Akt survival pathway through a redox-mediated mechanism. Journal of Cell Biology, 175, 913-923. doi:10.1083/jcb.200512100

[7] Kwong, J.Q., Henning, M.S., Starkov A.A. and Manfredi, G. (2007) The mitochondrial respiratory chain is a modulator of apoptosis. Journal of Cell Biology, 179, 11631177. doi:10.1083/jcb.200704059

[8] Majno, G. and Joris, I. (1995) Apoptosis, oncosis and necrosis: An overview of cell death. American Journal of Pathology, 146, 3-15. 
[9] Haraguchi, M., Torii, S., Matsuzawa, S., Xie, Z., Kitada, S., Krajewski, S., Yoshida, H., Mak, T.W. and Reed, J. (2000) Apoptotic protease activating factor 1 (Apaf-1)-I ndependent cell death suppression by Bcl-2. Journal of Experimental Medicine, 191, 1709-1720. doi:10.1084/jem.191.10.1709

[10] Mochizuki, T., Asai, A., Saito, N., Tanaka, S., Katagiri, H., Asano, T., Nakane, M., Tamura, A., Kuchino, Y., Kitanaka, C. and Kirino, T. (2002) Akt protein kinase inhibits non-apoptotic programmed cell death induced by ceramide. Journal of Biological Chemistry, 277, 2790-2797. doi:10.1074/jbc.M106361200

[11] Mills, E.M., Xu, D., Fergusson, M.M., Combs, C.A., Xu, Y. and Finkel, T. (2002) Regulation of oncosis by unupling protein 2. Journal of Biological Chemistry, 277, 27385-27392. doi:10.1074/jbc.M111860200

[12] Wu, Y.T., Zhang, S., Kim, Y.S., Tan, H.L., Whiteman, M., Ong, C.N., Liu, Z.G., Ichijo, H. and Shen, H.M. (2008) Signaling pathways from membrane lipid rafts to JNK1 activation in reactive nitrogen species-induced non-apoptotic cell death. Cell Death and Differentiation, 15, 386397. doi:10.1038/sj.cdd. 4402273

[13] Warburg, O. (1956) On the origin of cancer cells. Science, 123, 309-314. doi:10.1126/science.123.3191.309

[14] Warburg, O., Geissler, A.W. and Lorenz, S. (1967) On growth of cancer cells in media in which glucose is replaced by galactose. Hoppe-Seylers Zeitschrift fur Physiologische Chemie, 348, 1686-1687. doi:10.1515/bchm2.1967.348.1.1686

[15] Golshani-Hebroni, S.G. and Bessman, S.P. (1997) Hexokinase binding to mitochondria: A basis for proliferative energy metabolism. Journal of Bioenergetics and Biomembrane, 29, 331-338.

[16] Rodoriguez-Enriquez, S., Jaures, O., Rodoriguez-Zavala, J.S. and Moreno-Sanchez, R. (2001) Multisite control of the Crabtree affect in ascites hepatoma cells. European Journal of Biochemistry, 268, 2512-2519. doi:10.1046/j.1432-1327.2001.02140.x

[17] Simonnet, H., Alazard, N., Pfeiffer, K., Gallow, C., Beroud, C., Demont, J., Bouvier, R., Schaggar, H. and Godinot, C. (2002) Low mitochondria respiratory chain content correlates with tumor aggressiveness in renal cell carcinoma. Carcinogenesis, 23, 759-768. doi:10.1093/carcin/23.5.759

[18] Xu, R., Pelicano, H., Zhou, Y., Carew, J.S., Feng, L., Bhalla, K.N., Keating, M.J. and Huang, P. (2005) Inhibition of glycolysis in cancer cells: A novel strategy to overcome drug resistance associated with mitochondrial respiratory defect and hypoxia. Cancer Research, 65, 613- 621.

[19] Gogvadze, V., Orrenius, S. and Zhivotovsky, B. (2008) Mitochondria in cancer cells: What is so special about them. Trends in Cell Biology, 18, 165-173. doi:10.1016/j.tcb.2008.01.006

[20] Dang, C.V. and Semenza, G.L. (1999) Oncogenic alterations of metabolism. Trends in Biochemical Sciences, 24, 68-72. doi:10.1016/S0968-0004(98)01344-9

[21] Hanahan, D. and Weinberg, R.A. (2000) The hallmarks of cancer. Cell, 100, 57-70. doi:10.1016/S0092-8674(00)81683-9

[22] Elstrom, E.L., Bauer, D.E., Buzzai, M., Karnauskas, R., Harris, M.H., Plas, D.R., Zhuang, H., Cinalli, R.M.,
Alavi, A., Rudin, C.M., Craig, B. and Thompson, C.B. (2004) Akt stimulates aerobic glycolysis in cancer cells. Cancer Research, 64, 3892-3899. doi:10.1158/0008-5472.CAN-03-2904

[23] Ibsen, H. (1961) The Crabtree effect: A review. Cancer Research, 21, 829-841.

[24] Reitzer, L., Wice, B. and Kennel, D. (1979) Evidence that glutamine, not sugar, is the major energy source for cultured HeLa cells. Journal of Biological Chemistry, 254, 2669-2676.

[25] Rossignol, R., Gilkerson, R., Aggeler, R., Yamagata, K., James-Remington, S. and Capaldi, R.A. (2004) Energy substrate modulates mitochondrial structure and oxidative capacity in cancer cells. Cancer Research, 64, 985993. doi:10.1158/0008-5472.CAN-03-1101

[26] Marroquin, L., Hynes, J., Dykens, J.A., Jamieson, J.D. and Will, Y. (2007) Circumventing the Crabtree effect: replacing media glucose with galactose increases susceptibility of HepG2 cells to mitochondrial toxicants. Toxicological Sciences, 97, 539-547. doi:10.1093/toxsci/kfm052

[27] Jensen, S.R. and Schripsema, J. (2002) Chemotaxonomy and pharmacology of Gentianaceae. In: Struwe, L. and Albert, V. Eds., Gentianaceae-Systematics and Natural History. Cambridge University Press, London, 573-631.

[28] Matsukawa, K., Ogata, M., Hikage, T., Minami, H., Shitai, Y., Saitoh, Y., Yamashita, T., Ouchi, A., Tsutsumi, R., Fujioka, T. and Tsutsumi, K. (2006) Antiproliferative activity of root extract from gentian plant (Gentiana triflora) on cultured and implanted tumor cells. Bioscience, Biotechnology and Biochemistry, 70, 1046-1048. doi:10.1271/bbb.70.1046

[29] Matsukawa, K., Kamata, T., and Ito, K. (2009) Functional expression of plant alternative oxidase decreases antimycin A-induced reactive oxygen species production in human cells. FEBS Letters, 583, 148-152. doi:10.1016/j.febslet.2008.11.040

[30] Wall, M. and Wani, M. (1995) Campthotecin and taxol: discovery to clinic. Cancer Research, 55, 753-760.

[31] Qian, Y. Wang, H., Yao, W. and Gao, X. (2008) Aqueous extract of the Chinese medicine, Danggui-haoyao-san, inhibits apoptosis in hydrogen peroxide-induced PC12 cells by preventing cytochrome c release and inactivating of caspase cascade. Cell Biology International, 32, 30411.

[32] Fitch, M., Chang, C. and Parslow, T. (2000) The BH3 domain is required for caspase-independent cell death induced by Bax and oligomycin. Cell Death and Differentiation, 7, 338-349. doi:10.1038/sj.cdd.4400659

[33] Norberg, E., Orrenius, S. and Zhivotovsky, B. (2010) Mitochondrial regulation of cell death: Processing of apoptosis-inducing factor (AIF). Biochemical and Biophysical Research Communications, 396, 95-100. doi:10.1016/j.bbrc.2010.02.163

[34] Zhivotovsky, B. and Orrenius, S. (2010) Cell death meanisms: Cross-talk and role in disease. Experimental Cell Research, 316, 1374-1383. doi:10.1016/j.yexcr.2010.02.037

[35] Kroemer, G., Galluzzi, L., Vandenabeele, P., Abrams, J., Alnemri, E., Baehrecke, E., Blagosklonny, M., El-Deiry, W., Golstein, P., Green, D., Hengartner, M., Knight, R., Kumar, S., Lipton, S., Malorni, W., Nunez, G., Peter, M., Tschopp, J., Yuan, J., Piacentini, M., Zhivotovsky, B. and 
Melino, G. (2009) Classification of cell death: Recommendation of the nomenclature committee on cell death 2009. Cell Death and Differentiation, 116, 3-11. doi:10.1038/cdd.2008.150

[36] Eguchi, Y., Shimizu, S. and Tsujimoto, Y. (1997) Intracellular ATP levels determine cell death by apoptosis or necrosis. Cancer Research, 57, 1835-1840.
[37] Tomiyama, A., Serizawa, S., Tachibana, K., Sakurada, K., Samejima, H., Kuchino, Y. and Kitanaka, C. (2006) Crical role for mitochondrial oxidative phosphorylation in the activation of tumor suppressors Bax and Bak. Journal of the National Cancer Institute (USA), 98, 1462-1473. doi:10.1093/jnci/djj395 